\title{
RESEARCHES REGARDING THE CONTINUOUS IMPROVEMENT OF THE ABS (ANTI-LOCK BRAKING SYSTEM) OPERATION FOR THE PASSENGER CARS
}

\author{
Horia Beles ${ }^{\mathrm{a}}$, Alexandru Rus ${ }^{\mathrm{a}}$, George Dragomir ${ }^{\mathrm{a}}$, Tudor Mitran ${ }^{\mathrm{a}}$, Daniel Trusca ${ }^{\mathrm{b}}$, \\ Bogdan Tolea ${ }^{\mathrm{b}}$
}

\author{
${ }^{a}$ University of Oradea, Str. Universitatii, 1, Oradea 410087, Romania \\ ${ }^{b}$ University Transilvania of Brasov, Bdul. Eroilor, 29, Brasov, 500036, Romania
}

\begin{abstract}
This paper presents the validation for a simplified mathematical model of a passenger-car's ABS (Anti-Lock Braking System) for a "quarter-car" planar model was considered: a wheel in rotation movement and a mass in translational movement (the vehicle mass supported by that wheel), in accordance with the continuous improvement of the ABS (anti-lock braking system) operation for the passenger cars. The mathematical model consists in the motion equations of the wheel and "quarter-car" mass and in the equations describing the behaviour of the driver, controller, hydraulic module and brake. The model was transposed in a Matlab-Simulink model, offering the possibility to simulate many times how the ABS works if the constructive parameters, road conditions or driver inputs are changed. To validate a simplified model of a passenger car ABS (Anti-Lock Braking System) for a "quarter-car" planar model were conducted experimental researches in order to determine the braking performance of a vehicle on roads / runways with different adhesion coefficients.
\end{abstract}

Keywords: Model; vehicle dynamics; ABS; Matlab-Simulink; simulation
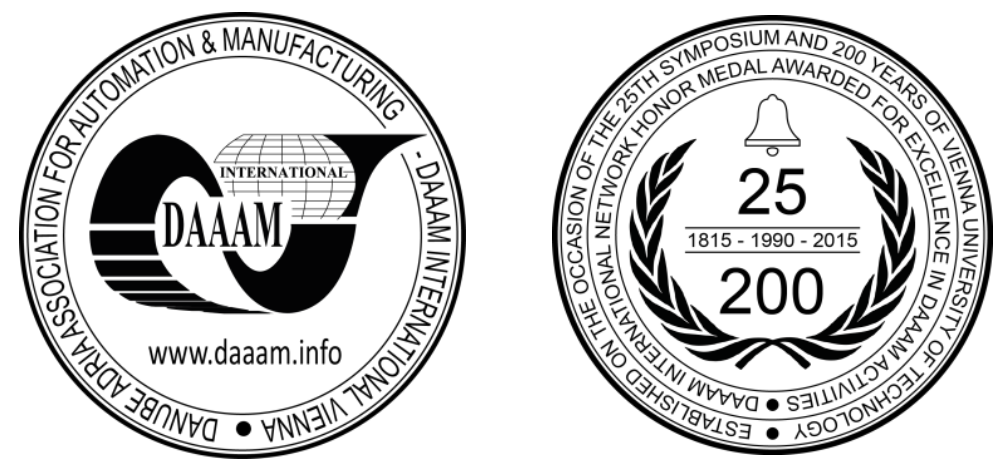

This Publication has to be referred as: Beles, H[oria]; Rus, A[lexandru]; Dragomir, G[eorge]; Mitran, T[udor]; Trusca, D[aniel] \& Tolea, B[ogdan] (2016). Researches Regarding the Continuous Improvement of the ABS (Anti-Lock Braking System) Operation for the Passenger Cars, Proceedings of the 26th DAAAM International Symposium, pp.0196-0205, B. Katalinic (Ed.), Published by DAAAM International, ISBN 978-3-902734-07-5, ISSN 1726-9679, Vienna, Austria DOI:10.2507/26th.daaam.proceedings.027 


\section{Introduction}

Anti-lock braking system (ABS) can improve the vehicle braking stability and steering performance, by using electronic control devices to adjust braking pressure for preventing the wheel from locking. Using the development of the automotive electronic control technology, many testing methods based on micro-processor were devised and the most important one is the hardware-in-the-loop simulation technology [7].

The vehicle's ABS system will regulate the wheel slip ratio around the demanded slip ratio range so that the road adhesion coefficient is maximized and lateral stability is achieved. Due to the different road characteristics of different types of road showed by Fig. 1, the ABS controller must identify the prevailing road condition first and then to be able to determine the corresponding optimal wheel slip range on line and, it would be more desired, without expensive road surface sensors.

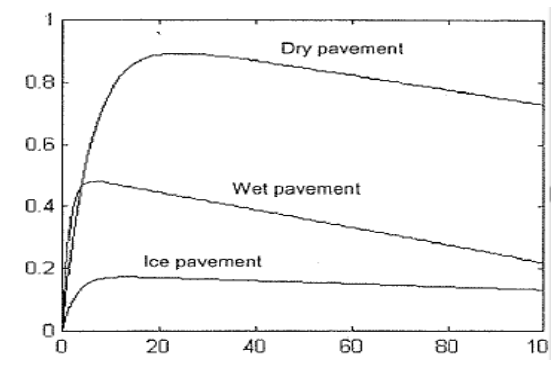

Fig. 1. Typical plots of road adhesion coefficient versus slip [8]

To check the ABS working algorithm and to emphasize the different influences on the braking process, with and without ABS, a planar dynamic model for a single wheel of the vehicle was conceived and used. The selected model has two inertial elements: a wheel and a mass in translational movement (the vehicle).

The influences of the suspension and direction mechanisms weren't explicitly took into consideration [4]. Also there were neglected the jerk and jumping movements of the wheel, respectively the lift up and pitch movements of the translational mass. These simplifications were realized deliberately to highlight the anti-lock braking system parameters that influence the braking process. In these conditions, the dynamic model has only two degrees of freedom: the wheel rotation around the spindle and the translation of the mass sustained by this wheel (including the wheel mass) on the travelling (longitudinal) direction [5].

\section{The model for ABS (Anti-Lock Braking System) simulation}

Simulink is a work module of the general mathematical calculus program Matlab (Mathworks Inc.). It is suitable for the simulation of technical systems because it has some valuable qualities [3]:

- It allows the description of the modeled system to use block diagrams interconnected with signal lines; so it results the ease in creation, understanding and use

- The block diagrams can be hierarchically grouped, which permits the description of some subassemblies and assemblies of great complexity

- The writing of the algebraic and differential equations with initial values which shows that the mathematical model of the system is done automatically

- For solving the mathematical model, more advanced methods of numerical integration are available

- The results of the simulation, obtained as a function of time, can be graphically represented in different ways

- The results obtained for one simulation can be stored in Matlab clipboard memory in order to obtain further analysis and comparisons

In Fig. 2, it is presented the main diagram of the Simulink model realized for the simulation of the ABS operating mode $[2,6,9,10,11]$.

The blocks that compose it are defined to permit the identification and understanding of the ABS functioning. The "Wheel" and "Vehicle" blocks correspond to the two degrees of freedom of the dynamic model - wheel rotation and "quarter" vehicle translation. These two movements are connected through the grip between the wheel and the road ("Adherence" block) that depends on the road properties defined in the "Road" block.

The comparator (the round block from the left side of the figure) calculates the difference between the desired values of the slip (the "Desired Slip" block) and the real slip (calculated in the "Adherence" block). Using this difference, the "Controller" block that simulates the operation mode of the adjustment algorithm implemented in the ABS computer will establish what kind of command must be executed by the ABS hydraulic assembly (modeled by "Hydraulic Modulator" block). The pressure generated by this is finally applied to the brake (modeled by the "Brake" block). 
Anti-lock braking system

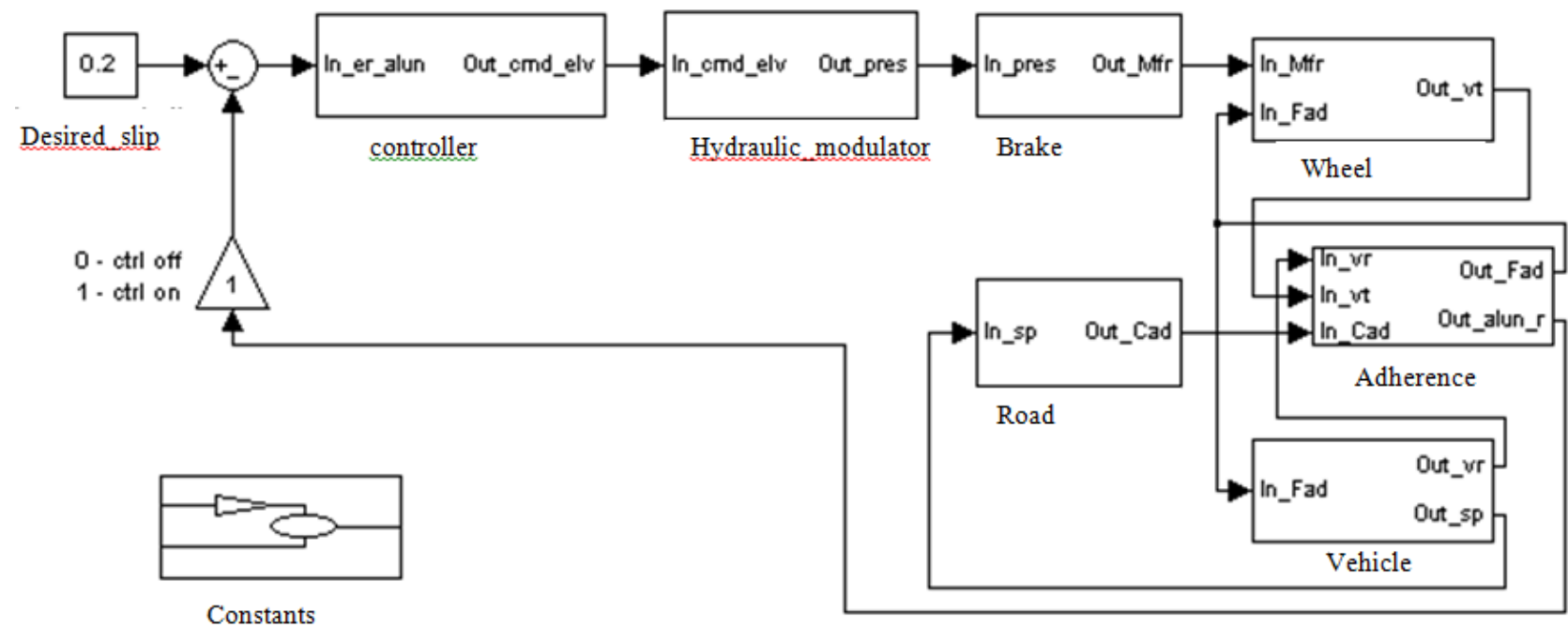

Fig. 2. Diagram of the Simulink model for ABS simulation

"Ctrl off / Ctrl on" block was introduced by the inverse connection path (to enable or disable the feedback loop) in order to simulate the same model both on an anti-lock braking system (ABS) and on a classic braking system (without ABS).

In order to adjust the wheel's running under braking, the manufacturers of braking systems watch to keep the deceleration, and the acceleration respectively, of the controlled wheel between two limit values, concomitant with the reaching of limit deceleration in a predetermined range. It is obvious that the operation of the adjustment algorithm based on the limit values of the wheel's acceleration, and the deceleration respectively, maintaining a predetermined time interval to reach the acceleration, supposed their determination through laborious experimental research made on representative road vehicles and representative wheels. For such an adjustment algorithm, the desiderate of maintaining the wheel in the stability zone of the running characteristic is a consequence of the experimental research.

To verify the operating algorithm of the ABS/ASR system and to highlight the different influences on the braking/starting process and without ABS, ASR respectively, a plan dynamic model was used, for one wheel of the vehicle. This simplified vehicle's model has to inertial elements: a wheel and a mass in translation (the road vehicle). Also for the simplification, the influences of the guiding mechanisms, of the suspension and of the steering systems were not explicitly taken into account. That means that the wheel's gasp and lift movements, and the lift and the pitching movements of the mass in translation respectively, were neglected. The limits mentioned above were made deliberately, for better highlighting the anti-lock braking system parameters that influence the braking process.

Even if it is very simple, the model was realized in a systemic vision, chasing the accentuation of the functional links between the different components of the ABS. Furthermore, simulations are presented on a car braking on a runway / dry asphalt road respectively a runway / road with different adhesion coefficient.

\subsection{Braking simulation when the vehicle is running on a road with dry asphalt}

Simulation parameters are presented in Fig. 3 and the conditions of the simulation are as follows:

- $\quad$ ABS on; Three states controller (able to increase, maintain or decrease the braking pressure)

- The maximal pressure in the hydraulic circuit is 90 bars; System delay equals to $0.005 \mathrm{~s}$

- Vehicle mass equals to $1200 \mathrm{~kg}$; The moment of inertia of the wheel equals to $0.75 \mathrm{kgm} 2$

- The braking initial speed (from which starts the braking) is $25 \mathrm{~m} / \mathrm{s}$

- The road surface has an adherence (grip) coefficient equals to 1 corresponding to a dry asphalt road

- Hydraulic gain equals to $5000 \mathrm{bar} / \mathrm{s}$ 


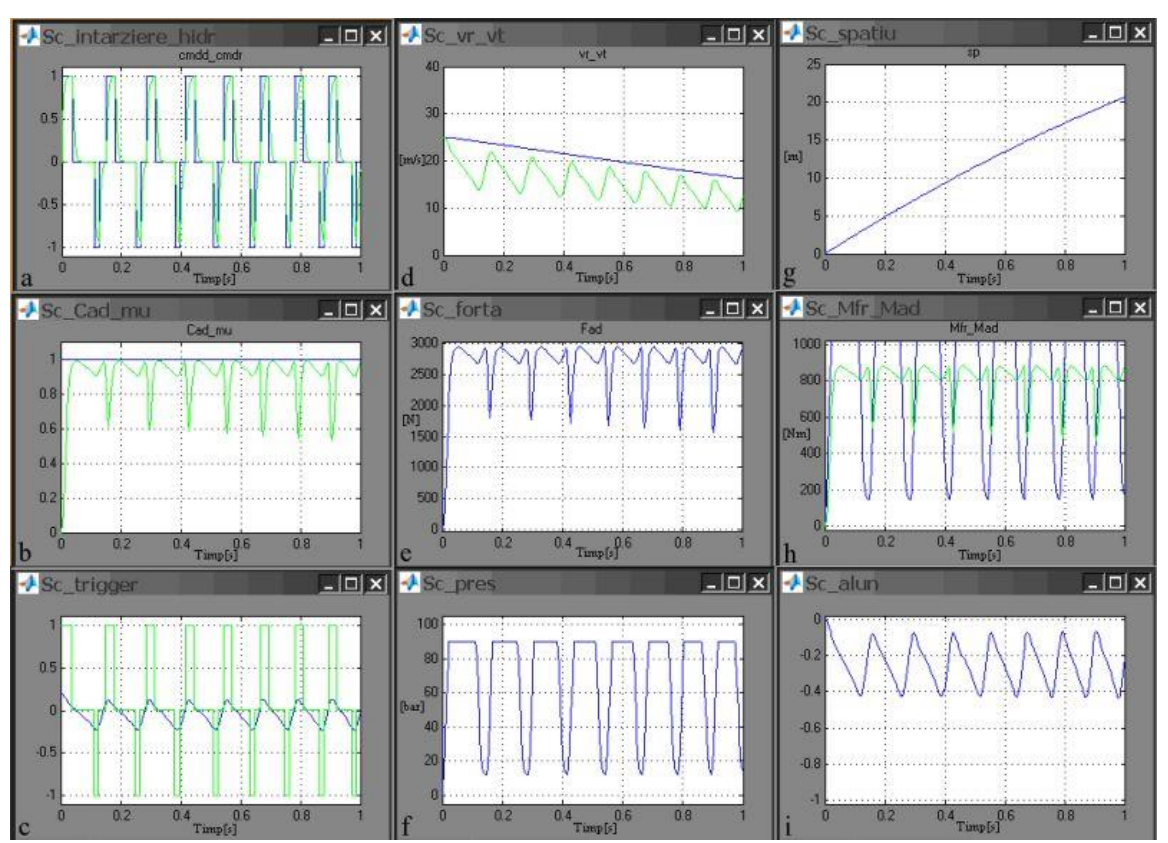

Fig. 3. Brake simulation results. a - hydraulic delay; where it can be seen the difference between the electro-valve command without the hydraulic delay and electro-valve command with the hydraulic delay; $b$ - road adherence coefficient and the utilized adherence coefficient; $\mathrm{c}$ - electro-valve command and the difference between the desired slip and the realized slip; $\mathrm{d}-$ the evolution in time of the real speed and of the theoretical speed; $\mathrm{e}$ - adherence force. $\mathrm{f}-$ pressure variation in the hydraulic circuit; $\mathrm{g}$ - distance traveled as function of time; $\mathrm{h}$ - braking moment and adherence moment; i - slip variation

\subsection{Braking performances on roads with different adherence coefficients}

For the next comparison it was used the results obtained from the braking simulation on roads with adherence coefficients of 1, 0.55, 0.2 and 0.1 that corresponds to dry asphalt, wet asphalt, snow and glaze (Fig. 4).

a

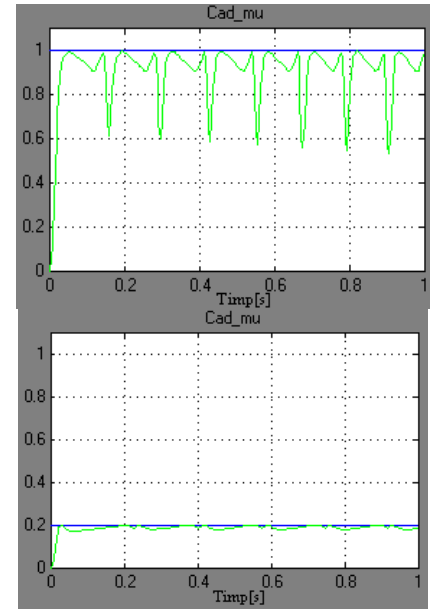

$\mathrm{b}$

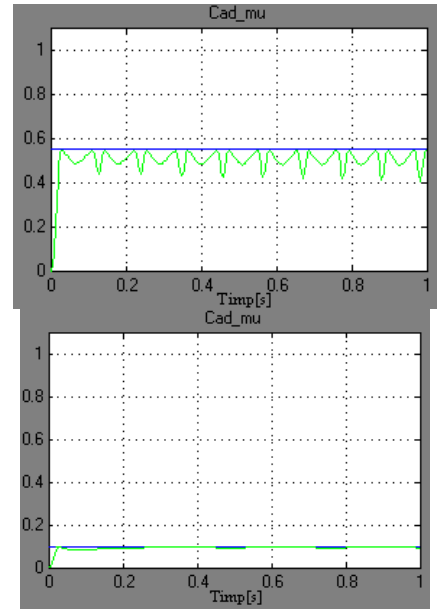

Fig. 4. Road adherence coefficient (blue) and used adherence coefficient (green): a - dry asphalt; $b$ - wet asphalt; csnow; $\mathrm{d}$ - glaze

The other simulation parameters are:

- Three state controller (it controls the decrease, the increase and the maintaining of the pressure value)

- The pressure in the hydraulic circuit is 75 bars

- The system delay is $0,005 \mathrm{~s}$

- The hydraulic gain is $5000 \mathrm{bar} / \mathrm{s}$

- The mass on one wheel is $300 \mathrm{~kg}$

- The inertia moment of the wheel is $0,75 \mathrm{kgm}^{2}$ 
- The velocity from which the vehicle starts to brake is $25 \mathrm{~m} / \mathrm{s}(90 \mathrm{~km} / \mathrm{h})$

Analyzing the results obtained for the used adherence coefficient it can be noticed a reduction of it with about $45 \%$ in the case of wet asphalt compared to the dry asphalt, which showed a reduction of $80 \%$ in case of snow and $90 \%$ in case of glaze.

Further on, there are presented the graphs corresponding to the pressures that are applied to the brake piston during the simulation on the four road conditions.

If on dry asphalt the commanded pressure avoids the lock of the wheel, on wet asphalt, in order to realize this and to obtain the best braking parameters, a faster variation of the pressure is required. On snow and glaze the tendency of the wheel to lock is higher, increasing also the time when the pressure has a low value in order to avoid this thing to take place.

In fact, in this period of time, the wheel tends to lock, but when the wheel is accelerated, the pressure is increased in order to brake the wheel. Because the wheel gets locked before the pressure reaches the maximum value, the pressure is decreased again, and the cycle is repeated. On the graphs where there are represented the slip, the speed and traveled distance, it can be seen that the brake efficiency decreases as the adherence coefficient gets lower, but at the same time the ABS system manages to use better the available adherence on glaze or ice than on dry asphalt.

As in the case of the used adherence coefficient, it can be seen that on the adherence force graph it is reduced to half, by comparing the simulations on dry and wet asphalt and those on snow and glaze. On the graphs that represent the electro valve command, the 1 value corresponds to its opening, 0 that it is maintaining the pressure and -1 when the pressure is decreased.

Variations of pressure in the hydraulic cylinder, slip, distance travelled, the adherence force and the working principle of the solenoid, depending of the road surface are shown in Fig. 5, 6, 7, 8 and 9.

a

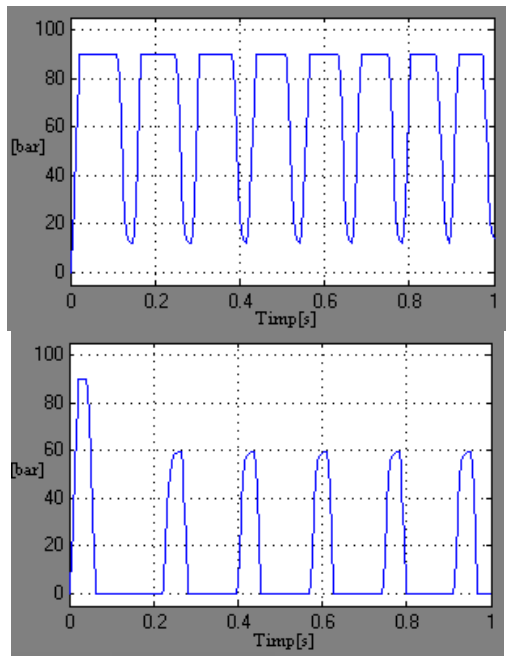

$\mathrm{b}$

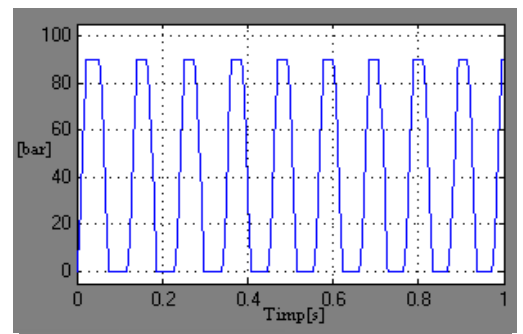

d

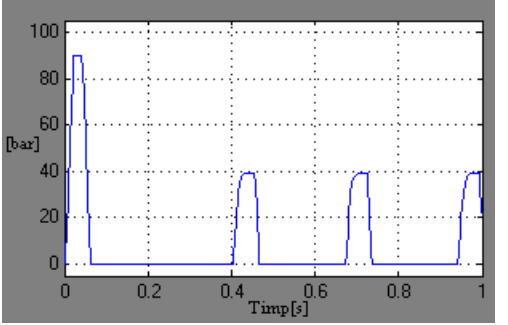

Fig. 5. Pressure in the hydraulic cylinder: $\mathrm{a}-$ dry asphalt; $\mathrm{b}-$ wet asphalt; $\mathrm{c}-$ snow; $\mathrm{d}-$ glaze

a

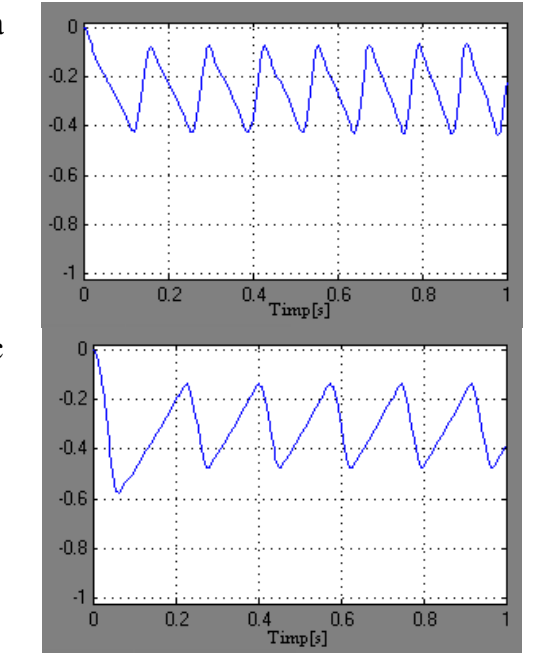

$\mathrm{b}$

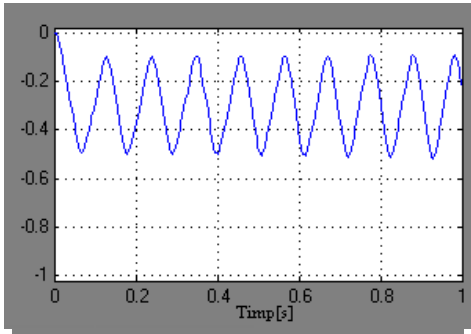

d

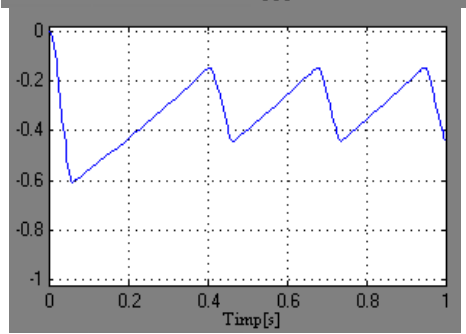

Fig. 6. Slip: $\mathrm{a}-$ dry asphalt; $\mathrm{b}-$ wet asphalt; $\mathrm{c}-$ snow; $\mathrm{d}$ - glaze 


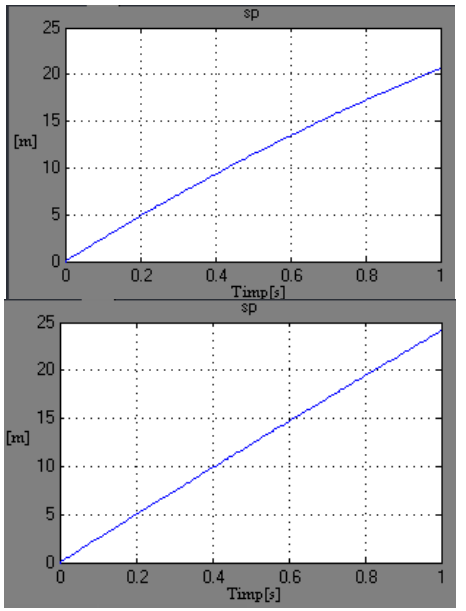

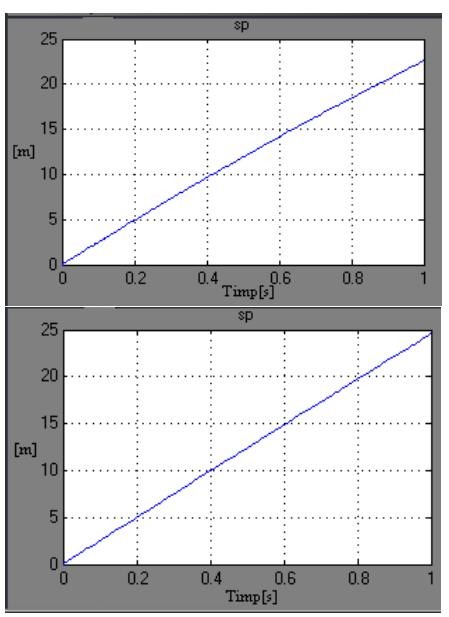

Fig. 7. Distance travelled: $\mathrm{a}-$ dry asphalt; $\mathrm{b}$ - wet asphalt; $\mathrm{c}-$ snow; $\mathrm{d}$ - glaze

a

c

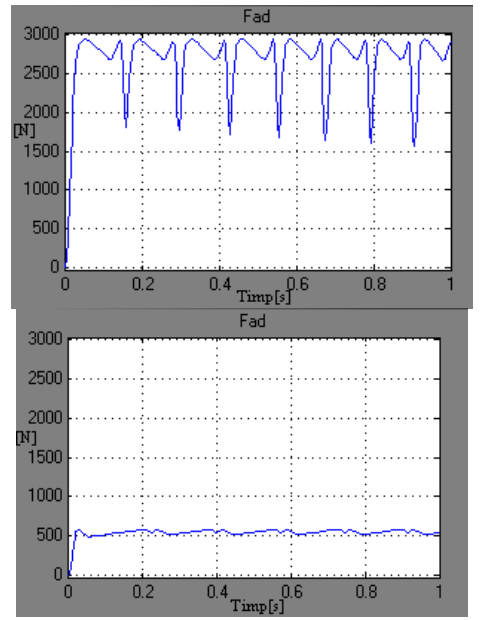

$\mathrm{b}$

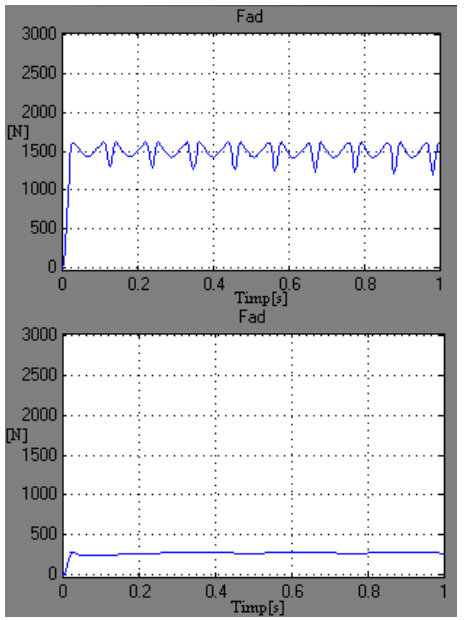

Fig. 8. The adherence force: $\mathrm{a}-$ dry asphalt; $\mathrm{b}-$ wet asphalt; $\mathrm{c}-$ snow; $\mathrm{d}$ - glaze

a

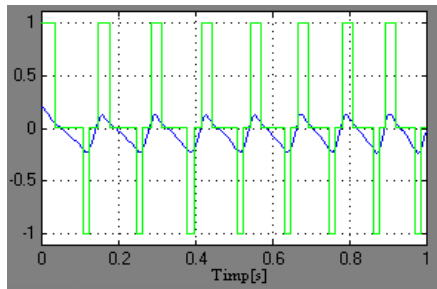

c

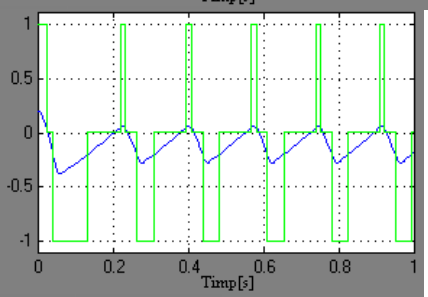

b

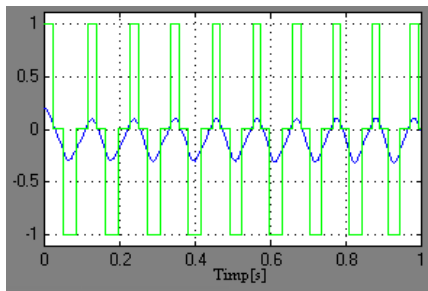

d

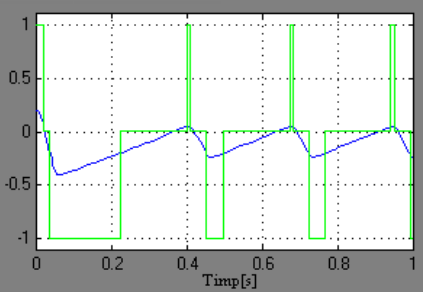

Fig. 9. Electro valve actuation (green) and the difference between the desired slip and the realized one (blue): a - dry asphalt; $\mathrm{b}$ - wet asphalt; $\mathrm{c}$ - snow; $\mathrm{d}$ - glaze

\section{Experimental tests regarding the performances of the braking system}

For measuring and recording the quantities, it was used a complex data acquisition system. Its disposal scheme is presented in Fig. 10. 


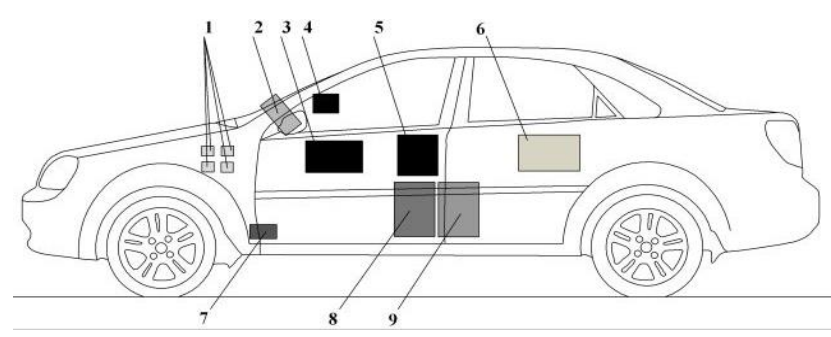

Fig. 10. Disposal scheme of data acquisition system components: 1 - pressure sensors; 2 - sensor for measuring the angle and the torque on the steering wheel; 3 - speed sensor (Datron); 4 - display; 5 - data logger; 6 - laptop; 7 sensor for the force on the braking pedal; 8 - signal amplifier; 9 - acquisition data device

The scheme presenting the utilized equipment interconnections, during the experimental research, is presented in Fig. 11.
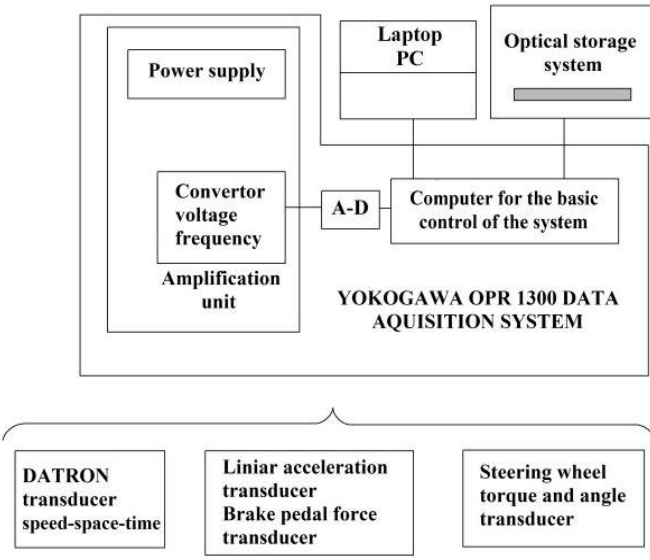

Fig. 11. Interconnecting scheme of the equipment utilized during the experimental research

For each test, the testing conditions, different in at least one aspect, were marked. To find the ABS behavior and performances during the braking of the vehicle, many experimental records were made, in different conditions. For easier identification and data processing, the records were grouped on set S1 and test (P1...P11). Further, the set S1 will be presented. In this set, the following tests were realized (Table 1) [1].

\begin{tabular}{lll}
\hline Set no. & Test no. & Test description \\
\hline & P1 & Linear braking (with ABS) on dry asphalt, with the engine out of gear \\
& P2 & Linear braking (with ABS) on a surface with different adherence left/right \\
& P3 & Linear braking (with ABS) on a surface with different adherence left/right \\
& P4 & Linear braking (with ABS) on a surface with dry cubic stone \\
& P5 & Linear braking (with ABS) passing from dry cubic stone on dry asphalt \\
S1 & P6 & Braking when turning right (with ABS) on dry asphalt \\
& P7 & Linear braking (with ABS) on dry asphalt \\
& P8 & Linear braking (without ABS) on a surface with different adherence left/right \\
& P9 & Braking when turning right (without ABS) on dry asphalt \\
P10 & Linear braking (without ABS) passing from dry cubic stone on dry asphalt \\
P11 & Linear braking (without ABS) on dry asphalt \\
\hline
\end{tabular}

Table 1. Tests description

Further on there are presented the data recorded at some of the the tests previously described.

\subsection{P7. Linear braking (with $A B S$ ) on dry asphalt}

For the previous records, the braking test S1-P7 (Linear braking with ABS on dry asphalt) will be presented further on. Graphic evolution of the measured sizes is shown in Fig. 12. This test was performed in the following conditions: 
- Linear braking, with warm brakes

- Adherence coefficient on the left: 1.0 (dry asphalt)

- Adherence coefficient on the right: 1.0 (dry asphalt)

- The initial vehicle speed (at which starts the braking): $82,2 \mathrm{~km} / \mathrm{h}$

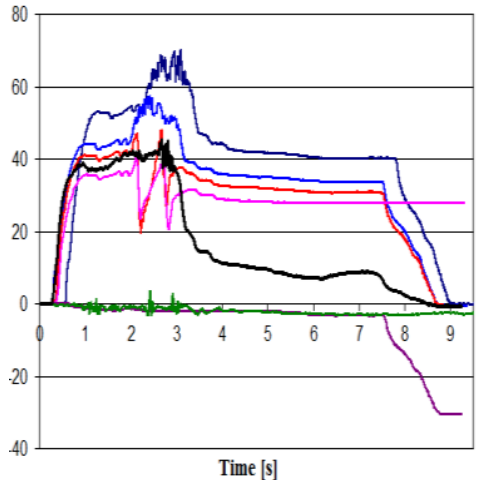

a

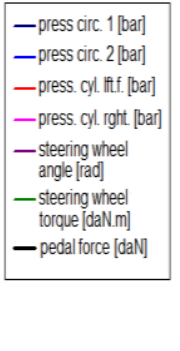

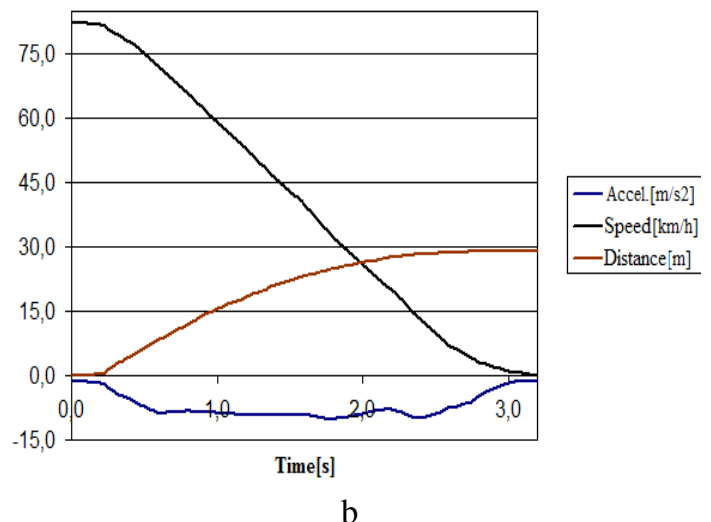

$\mathrm{b}$

Fig. 12. Linear braking (with ABS) on dry asphalt: a - the pressure in the braking circuit, the pressure in the braking cylinder, steering wheel angle, steering wheel torque and the force on the pedal measured with the data acquisition system; b - Acceleration, speed and distance measured with the DATRON system

\subsection{P2. Linear braking (with ABS) on a surface with different adherence left/right}

Graphic evolution of the sizes measured is shown in Fig. 13. This probe was performed in the following conditions:

- Linear braking, with warm brakes

- Adherence coefficient on the left: 1.0 (dry asphalt)

- Adherence coefficient on the right: 0.6 (dry concrete covered with gravel)

- The initial vehicle speed (at which starts the braking): $66,2 \mathrm{~km} / \mathrm{h}$

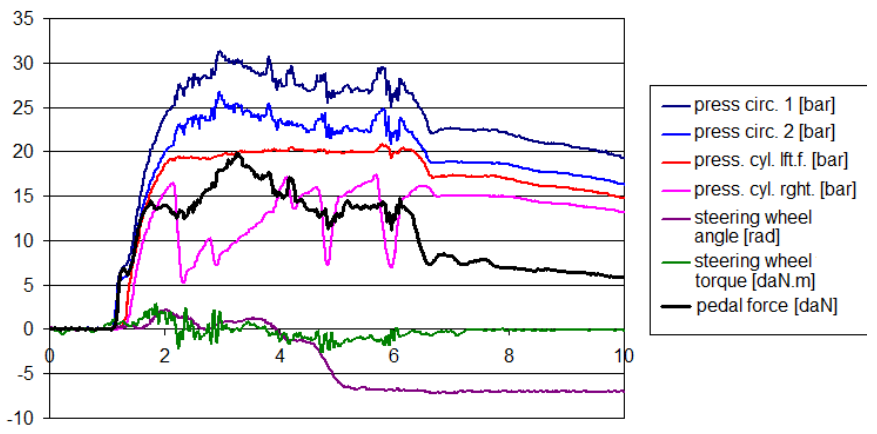

a

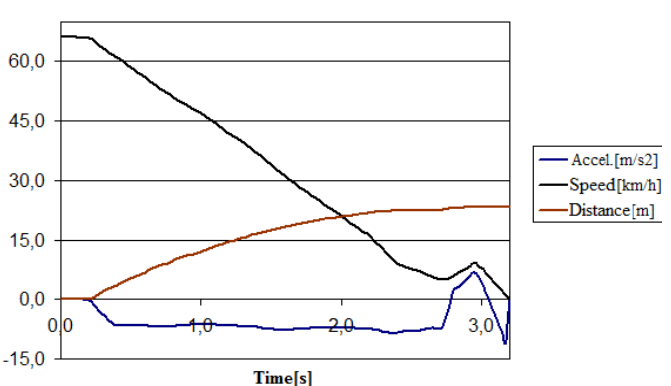

$\mathrm{b}$

Fig. 13. Linear braking (with ABS) on a surface with different adherence left/right: a - the pressure in the braking circuit, the pressure in the braking cylinder, steering wheel angle, steering wheel torque and the force on the pedal measured with the data acquisition system; b - Acceleration, speed and distance measured with the DATRON system

\section{The comparative analysis of the theoretical and experimental results}

Part of the experimental records, made in controlled and well known conditions, were used to calibrate the model (i.e. to fine tune its input values as gain, delays, etc.) and to validate it. Then, the results obtained by simulation were compared with the other experimental results [1].

The Fig. 14.a and 14.b present the comparative analysis of the data obtained by simulation using the mathematical model developed respectively similar sizes measured in the experimental research, when braking on a surface with dry asphalt. 


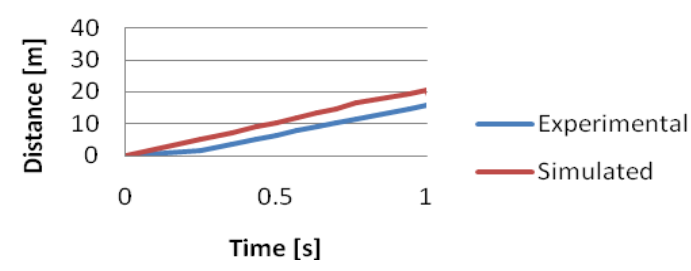

a

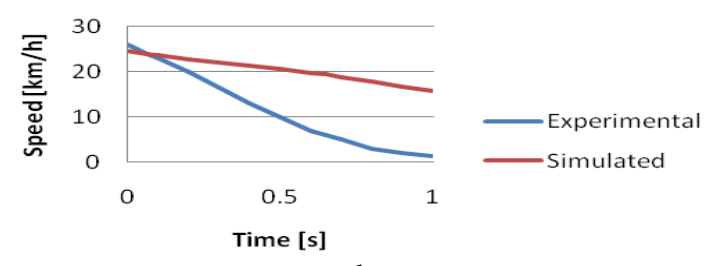

b

Fig. 14. Comparative analysis: a - braking distance vs. time; braking on dry asphalt; $\mathrm{b}$ - the evolution of the speed; braking on dry asphalt

The experimental conditions for the braking process presented in Fig. 14.a and 14.b (with blue line), were:

- $\quad$ Rectilinear braking (with ABS), with warm brakes

- Dry asphalt road

- The velocity from which the braking starts is $22.8 \mathrm{~m} / \mathrm{s}$

The simulation parameters for the braking process simulated in Fig. 14.a and 14.b (with brown line), were quite similar:

- Dry asphalt road (constant grip coefficient, equal with 1), for all the wheels

- The braking initial velocity is $25 \mathrm{~m} / \mathrm{s}$

- The vehicle mass is $300 \mathrm{~kg}$ per wheel

- The inertia moment of the wheel is $0.75 \mathrm{kgm}^{2}$

- The maximal pressure in the hydraulic circuit is 90 bars

- Three states controller (able to increase, maintain or decrease the braking pressure)

Comparing the experimental results with the theoretical results obtained by simulation, it can be seen that the results obtained mathematically have similar evolutions according to those determined by measurements.

This proves that the simulation model realized and presented in this paper surprises accurately enough the phenomena related to the braking dynamics of the wheel of the car.

\section{Conclusion}

The technical solutions successfully applied to the braking domain were followed by the bond of using antilock braking systems (ABS), at first for the heavy vehicles, and nowadays a real offensive trend to extend these systems on small and medium vehicles.

Even if there tends to be a lot of theoretical and experimental researches worldwide, the large number of factors that influence the braking process lead to the conclusion that the problems regarding this system still remain open for further studies

Even if the ABS systems have already been in the series production, with well known basic principles and layouts, the CPU algorithms used to adjust the brakes actuation have specific particularities for each producer, through each solution being followed the goal of carrying out all the performance criteria imposed by the actual regulations.

The main objective of this work was to realize a simplified mathematical model of the vehicle that allows the simulation of the braking process, to be able to reproduce with enough accuracy the ABS behavior. This goal was largely achieved.

The novelty of this research paper is represented by the definition of the simplified mathematical model of a passenger-car's ABS for one single wheel ("quarter-car") taking into account: a wheel in rotation movement and a mass in translational movement (the vehicle mass supported by that wheel), in accordance with the optimization of the ABS (anti-lock braking system) operation. The author's personal contributions are determined by the transposition of this simplified mathematical model into a new model Matlab-Simulink, offering the possibility to simulate many times the ABS activity and to simulate the constructive parameters, the road conditions or the changes of the driver's inputs for a better optimization. Such mathematical model developed was validated using the data obtained through the experimental research.

\section{References}

[1] H. Beles, The research regarding the development of active safety for passenger cars in order to reduce the accidents with serious consequences, Doctoral thesis (in Romanian), "Transilvania” University, Brasov, 2007.

[2] R. Verma, D. Ginoya, PD. Shendge, SB. Phadke. Slip regulation for anti-lock braking systems using multiple surface sliding controller com-bined with inertial delay control. Vehicle System Dynamics, Volume 53, Issue 8, pp 1150-1171 DOI 10.1080/00423114.2015.1026831

[3] Matlab Simulink tutorial, 2007. Modelling an Anti-Lock Braking System. 
[4] I. Preda, I. Todor, Gh. Ciolan, Contributions to the simulation of vehicle longitudinal dynamics. In: Bulletin of the “Transilvania” University of Brasov, vol. 12 (47), Seria A1, pp. 177-186, ISSN 1223-9631, Brasov, 2005.

[5] I. Preda, Gh. Ciolan, Wheel-road interaction modelling. CAR Pitesti, 1997, pp. 85-90.

[6] H. Mirzaeinejad, M. Mirzaei. Optimization of nonlinear control strategy for anti-lock braking system with improvement of vehicle directionnal stability on split-mu roads. Transportation Research part C-Emerging Technologies, Volume 46, Pages 1-15, DOI: 10.1016/j.trc.2014.05.003

[7] Huiyi Wang, Bo Gao, Jian Song, Approach of Debugging Control Laws of ABS Combined with Hardware in the Loop Simulation and Road Experiment, pp 209-212, 2001-01-2729 in Electronic Braking, Traction, and Stability Controls volume 2.

[8] Li Jun, Zhang Jianwu and Yu Fan, Investigation into Fuzzy Control for Anti-Lock Braking System Based on Road Autonomous Identification, pp 219-225, 2001-01-0599 in Electronic Braking, Traction, and Stability Controls volume 2 .

[9] H. Beles, I. Preda, G. Dragomir, V. Blaga, F. Ardelean, Theoretical Research Regarding the Active Safety Systems. Annals of DAAAM for 2008 \& Proceedings of the 19th International DAAAM Symposium. ISBN 9783-901509-68-1, ISSN 1726-9679, pp 0087-0088.

[10] H. Beleş, G. Dragomir, T. Mitran, F. Ardelean, V. Popa. Theoretical research regarding the braking performances of the passenger cars on roads with different adherence coefficients, in concordance with the improvement of active safety and the reduction of accidents with severe consequences. Annals of the 8th International Conference ESFA 2009, Bucharest. Volume 2, ISSN 2067-1083, pp 343 - 352.

[11] H. Beleş, T. Nagy, I. Preda. Research regarding vehicles braking and the influence on active safety. Annals of International Congress SMAT 2008. Automotive, Safety and Environement. Second edition. Vol. 1: Road vehicles - Tractors and machinery for agriculture, ISBN 978-606-510-253-8, 978-606-510-245-3, pp. 253 - 260. Publishing House UNIVERSITARIA Craiova, 2008. 